\title{
Lead-induced increase in erythrocyte osmotic fragility and malondialdehyde concentration in Wistar rats: Chemo-protective effects of flavonoid mixture
}

\author{
Yusuf I. L. ${ }^{1}$, Akef I. O. ${ }^{2 \star}$, Tijjani M. B. ${ }^{1}$, Yusuf H. ${ }^{3}$, Salihu S. I. ${ }^{1}$ and Muhammad Z. \\ ${ }^{1}$ Veterinary Pharmacology and Toxicology, University of Maiduguri, Nigeria. \\ ${ }^{2}$ Veterinary Physiology, Ahmadu Bello University, Zaria, Nigeria. \\ ${ }^{3}$ Clinical Pharmacy and Pharmacy Administration, University of Maiduguri, Nigeria. \\ ${ }^{4}$ Human Physiology, Ahmadu Bello University, Zaria, Nigeria.
}

Accepted 23 December, 2017

\begin{abstract}
Lead has been affirmed as a potent toxicant impairing physiological functions and causing innumerable perturbations at cellular and tissue levels. Daflon ${ }^{\circledR} 500 \mathrm{mg}$ is a flavonoid fraction of Rutaceae aurantiae comprising $90 \%$ diosmin and $10 \%$ hesperidin. The aim of this study was to evaluate the effect of flavonoid mixture against cellular injury caused by lead-induced generation of free radicals. Forty adult male Wistar rats divided into five groups of eight animals each were used for the experiment. Group I was administered distilled water only. Group II: lead (250 mg/kg BW), group III: lead (250 mg/kg BW) followed by dimercaptosuccinic acid (DMSA) $(10 \mathrm{mg} / \mathrm{kg} \mathrm{BW})$, group IV: lead $(250 \mathrm{mg} / \mathrm{kg} \mathrm{BW})$ followed by Daflon ${ }^{\circledR}(100$ $\mathrm{mg} / \mathrm{kg} \mathrm{BW})$ and group V: lead $(250 \mathrm{mg} / \mathrm{kg} \mathrm{BW})$ followed by Daflon ${ }^{\circledR}(100 \mathrm{mg} / \mathrm{kg} \mathrm{BW})$ and DMSA $(10 \mathrm{mg} / \mathrm{kg}$ BW). The xenobiotics were all administered orally. At the end of four weeks, EDTA-blood samples and serum samples were collected from the rats, and were used to evaluate changes in erythrocyte osmotic fragility and lipid peroxidation, respectively. Experimental exposure of rats to lead caused an increase in erythrocyte osmotic fragility (EOF) and lipid peroxidative changes, while administration of Daflon ${ }^{\circledR}$ ameliorated the ensued damages. In conclusion, is plausible that the flavonoid mixture alleviated the detrimental effects of lead toxicity via its membrane stabilization, cytoprotective and osmoregulatory potentials.
\end{abstract}

Keywords: Lead, flavonoid, Daflon ${ }^{\circledR}$, erythrocyte fragility, lipid peroxidation.

*Corresponding author. E-mail: akefeisaac@yahoo.com.

\section{INTRODUCTION}

Lead is currently one of the most important environmental toxicant globally. Lead poisoning is typified by a rapid decline in erythrocyte counts, hemoglobin concentration and packed cell volume, affirming anemia as a critical facet in pathogenesis of lead toxicity (Warang et al., 2017).

Tissue damage has also been reported in the pathophysiology of lead poisoning, with increasing evidence that oxidative stress plays an important role in the pathology of lead poisoning (Jalali et al., 2017).

The erythrocyte membrane is rich in polyunsaturated fatty acids, rendering it more vulnerable to free radicalinduced lipid peroxidative changes (Ambali et al., 2010;
Wahab et al., 2010). By-products of lipid peroxidation have been shown to trigger intense alterations in the structural and functional organization of the cell membrane, including decline in membrane fluidity, enhanced membrane permeability, inactivation of membrane-bound enzymes and loss of essential fatty acids (Kolanjiappan et al., 2002; Ambali et al., 2010). These alterations in the cell surface of erythrocytes, leads to a considerable upsurge in erythrocyte osmotic fragility (EOF) (Saluja et al., 1999). Lead intoxication has also been proven to cause alterations in antioxidant defense mechanism (Adnan et al., 2017), thus, increasing the susceptibility of erythrocytes to oxidative hemolysis (Jalali 
et al., 2017).

The conventional treatment of lead poisoning has been chelation using drugs such as Dimercaprol, Ethylene diamine tetraacetic acid (EDTA), Succimer (DMSA) and D-penicillamine (Kessel and O'Connor, 2001).

Synthetic chelators have however been associated with some side effects, high cost, complex methods of production, potential for eliciting immunogenic responses, time needed to generate them, and stability issues; which are limiting their utilization and effectiveness as clinical agents. These factors exacerbate the global challenge of providing alternative therapeutic measures for lead toxicity (Weisman et al., 2015). In underdeveloped nations of sub Saharan Africa with rampant lead poisoning, the cost of chelation therapy is considered a major problem (Cheong and Roh, 2006). There is therefore need to explore readily available and natural occurring compounds in the management and treatment of lead poisoning.

Flavonoids are effective antioxidants owing to their ability to chelate active metal ions and inhibit the initiation of free radical chain reaction (Terao, 2009; Maikai et al., 2011).

Daflon $^{\circledR} 500 \mathrm{mg}$ is a vasoprotector and venotonic agent, which active component is the micronized purified flavonoid fraction of Rutaceae aurantiae, consisting of $90 \%$ diosmin and $10 \%$ hesperidin as bioactive components (Rizk and Sabri, 2009). The aim of this study was to evaluate the effect of Daflon ${ }^{\circledR} 500 \mathrm{mg}$ against cellular injury caused by lead-induced generation of free radicals.

\section{MATERIALS AND METHODS}

\section{Experimental animals}

A total of 40 adult male Wistar rats, weighing between 250 and 300 $\mathrm{g}$ were used for the experiment. The animals were obtained from the Animal House of the Department of Veterinary Pharmacology and Toxicology, Ahmadu Bello University, Zaria, Nigeria. They were allowed to acclimatize for 14 days in the toxicology research laboratory, where the experiment was conducted. The rats were housed under standard laboratory conditions (ambient temperature of 24 to $26^{\circ} \mathrm{C}$, relative humidity 70 to $80 \%$, with $12 \mathrm{~h} /$ day light period) in plastic cages with wood shavings as bedding, which was changed weekly. They were given free access to rat pellets and water ad libitum. The experiments followed the principles of the laboratory animal care (CACC, 1993).

\section{Chemicals}

Lead and dimercaptosuccinic acid (DMSA), both analytical grades, were purchased from Sigma Aldrich (St. Louis, MO, USA) and Daflon-500 ${ }^{\circledR}$ from Servier, Neuilly-Surseine, France.

\section{Experimental design}

Forty adult male Wistar rats (250 to $300 \mathrm{~g}$ ) were randomly assigned to five experimental groups, eight animals in each. Group I was unexposed control animals that were administered distilled water only. Group II was administered with lead ( $250 \mathrm{mg} / \mathrm{kg} \mathrm{BW})$, group III was administered with lead $(250 \mathrm{mg} / \mathrm{kg} \mathrm{BW})$ followed by DMSA (10 $\mathrm{mg} / \mathrm{kg} \mathrm{BW}$ ), group IV was administered with lead (250 mg/kg BW) followed by Daflon ${ }^{\circledR}(100 \mathrm{mg} / \mathrm{kg}$ BW $)$ while group $\mathrm{V}$ was administered with lead $(250 \mathrm{mg} / \mathrm{kg} \mathrm{BW})$ followed by Daflon ${ }^{\circledR}(100$ $\mathrm{mg} / \mathrm{kg}$ BW) and DMSA (10 $\mathrm{mg} / \mathrm{kg}$ BW). All regimens were administered once daily via oral gavage for a period of four weeks (28 days).

\section{Blood collection}

At the end of the experiment, all of the rats were exposed to mild ether anaesthesia and three $\mathrm{mL}$ of blood was collected from the internal jugular vein of each rat into EDTA containing sample bottle and plain clean sample bottle for determination of EOF and serum MDA, respectively. Blood in the plain sample bottles was allowed to coagulate at room temperature $\left(24\right.$ to $\left.26^{\circ} \mathrm{C}\right)$ and, thereafter, centrifuged at $1000 \times \mathrm{g}$ for $10 \mathrm{~min}$. Serum was collected in clean bottles and stored at $4^{\circ} \mathrm{C}$ until further analysis.

\section{In vitro determination of erythrocyte osmotic fragility}

Erythrocyte osmotic fragility was determined as described by Faulkner and King (1970) as modified by Oyewale (1991). Briefly, sodium chloride solution $(\mathrm{pH} 7.4)$ was prepared at varying concentrations, $0.0,0.1,0.3,0.5,0.7 \%$ and $0.9 \%$. Five milliliters $(5$ $\mathrm{ml}$ ) of each $\mathrm{NaCl}$ concentration was placed in labelled test tubes serially. Exactly $0.02 \mathrm{ml}$ of the blood sample was pipetted into each tube. The tubes were gently mixed by inverting the tubes and allowing them to stand at room temperature $\left(24\right.$ to $\left.26^{\circ} \mathrm{C}\right)$ for $30 \mathrm{~min}$. Thereafter the tubes were centrifuged at $1580 \times \mathrm{g}$ for 5 min using a centrifuge model IEC HN-SII (Damon/IEC Division, UK). The supernatant obtained from each tube was transferred into a clean glass cuvette and the absorbance of the supernatant measured spectrophotometrically with Spectronic 20 (Bausch and Lomb, USA) at $540 \mathrm{~nm}$. The percentage of hemolysis for each sample was calculated using the following formula:

$$
\text { Hemolysis }(\%)=\frac{\text { Optical density of test solution }}{\text { Optical density of standard solution (distilled water) }} \times 100
$$

\section{Determination of serum malondialdehyde concentration}

The concentration of MDA was measured using rat specific ELISA kit (Cloud-Clone Corp, Houston, TX, USA), according to the manufacturer's instructions. The test principle applied in this kit is sandwich enzyme immunoassay. Briefly, purified standards, blanks, and sera $(50 \mu \mathrm{l})$ were added to microplate wells, precoated with monoclonal anti-MDA antibody. A biotin conjugated polyclonal antibody specific for MDA $(50 \mu \mathrm{l})$ was added to each well and incubated for $1 \mathrm{~h}$ at $37^{\circ} \mathrm{C}$. Following washing of the wells (4 times), an avidin conjugated to horseradish peroxidase solution was added and incubated for $30 \mathrm{~min}$ at $37^{\circ} \mathrm{C}$. After washing of the wells $(5$ times), a 3,3,5,5 tetramethylbenzidine (TMB)-substrate solution was added to the wells and the plate incubated for $25 \mathrm{~min}$ at $37^{\circ} \mathrm{C}$. The reaction was stopped by the addition of sulphuric acid (stop solution) and absorbance read on a microplate reader (MultiskanEX, Thermo Fisher Scientific Instruments Co. Ltd, Shanghai, China) at $450 \mathrm{~nm}$. Standard curves were generated by plotting the optical density of the standard (X-axis) against the log of known concentration of the standard (Y-axis). Values were extrapolated and normalized to the protein concentration of each 
sample.

\section{Statistical analysis}

Data obtained were expressed as mean \pm SEM and subjected to one-way analysis of variance (ANOVA), followed by Tukey's multiple comparison post-hoc test, using GraphPad Prism version 5.0 for windows (GraphPad Software, San Diego, California, USA). Values of $\mathrm{P}<0.05$ were considered significant.

\section{RESULTS}

\section{Erythrocyte osmotic fragility}

The percentage erythrocyte osmotic fragility decreased with increasing $\mathrm{NaCl}$ concentration $(0 \%$ to $0.9 \%)$ in all the treatment groups. There was a significant decrease $(\mathrm{P}<0.05)$ in the percentage hemolysis of rats in group $\mathrm{V}$ exposed and treated with Daflon ${ }^{\circledR}$ and DMSA (85.00 \pm $1.37,83.13 \pm 1.15$ ) when compared to group II exposed untreated $(92.25 \pm 1.40,91.63 \pm 2.53)$ at 0.1 and $0.3 \%$ $\mathrm{NaCl}$ concentration, respectively. However, there was a consistent decrease in percentage hemolysis in groups exposed and treated with DMSA $(22.88 \pm 0.67,17.19 \pm$ $1.05,14.38 \pm 1.07)$, exposed and treated with Daflon ${ }^{\circledR}$ $(12.50 \pm 0.59,12.38 \pm 0.58,9.76 \pm 0.30)$, exposed and treated with Daflon ${ }^{\circledR}$ and DMSA (8.36 $\pm 0.47,6.71 \pm 0.40$, $5.41 \pm 0.55)$ when compared to the exposed untreated group $(70.25 \pm 1.10,50.50 \pm 1.10,40.56 \pm 1.52)$ at 0.5 , 0.7 and $0.9 \% \mathrm{NaCl}$ concentration respectively (Figure 1 ).

\section{Serum malondialdehyde concentration}

The effect of treatments on serum MDA concentration is shown in Figure 2. There was a significant $(P<0.001)$ increase in the serum MDA concentration in the lead exposed untreated group (group II) $(3.21 \pm 0.10)$, when compared to the control and all other treatment groups. The serum MDA concentration in the group exposed to lead and treated with the combination of Daflon ${ }^{\circledR}$ and DMSA (group V) $(0.84 \pm 0.07)$ was significantly $(P<0.05)$ lower than that obtained in any other group apart from the control (group I) $(0.2 \pm 0.02)$. Furthermore, there was a significant decrease $(P<0.05)$ in MDA concentration in group IV exposed treated with Daflon ${ }^{\circledR}(1.52 \pm 0.16)$ when compared to group III exposed with lead and treated with DMSA $(2.65 \pm 0.16)$ and group II exposed with lead and untreated $(3.21 \pm 0.10)$, respectively.

\section{DISCUSSION}

Erythrocyte osmotic fragility (EOF) which measures the extent of resistance of erythrocyte to intracellular pressure is known to be a biomarker of or lipid peroxidation (Asala et al., 2011). Exposure of rats to lead induced a significant increase in erythrocyte osmotic fragility (EOF) in the experimental animals. This result is in line with previous studies as carried out by Jalali et al. (2017), who found similar results as that reported in this study. The increase could be ascribed to the increase in the generation of reactive oxygen species (ROS) following oxidative damage, as caused by lead. Flora (2002), also reported that exposure to heavy metals, such as lead, may alter the antioxidant defense against free radicals resulting to over production of ROS or depletion of antioxidants. Free radicals capture electrons from the phospholipids present inside the erythrocyte membrane and damage the cell. Lead also causes oxidation of hemoglobin, thus inducing erythrocyte hemolysis owing to the inhibition of aminolevulinic acid dehydratase (ALAD). Inhibition of ALAD further results in an increased concentration of substrate aminolevulinic acid (ALA) in both blood and urine. These elevated ALA levels generate hydrogen peroxide and superoxide radical formation and also interact with oxyhemoglobin, resulting in the generation of hydroxyl radicals (Patrick, 2006).

According to the above mentioned mechanisms, the cell becomes extremely vulnerable to oxidative stress, loss of erythrocyte membrane integrity and subsequent lysis of the cell. This study revealed that the erythrocytes of the lead exposed group were more susceptible to hemolysis, suggesting that the erythrocytes had undergone some deleterious surface membrane changes, which increased susceptibility to hemolysis. The results of present study are consistent with the findings of Debosree et al. (2016), who reported increased EOF in rats exposed to lead. Loss of membrane symmetry and an increase in membrane permeability, inducing morphological changes in the surface of erythrocytes have been demonstrated to increase EOF (Ambali et al., 2010). The changes on the surface of erythrocyte membranes caused by lead exposure could partly be responsible for the increased EOF, as was found in the exposed group. The erythrocytes of the exposed and treated groups were protected from significant EOF because of the treatment with Daflon ${ }^{\circledR} 500 \mathrm{mg}$, which is a flavonoid mixture, and flavonoids have been reported to be effective antioxidants (Terao, 2009) known to stabilize free radicals and inhibit free radical-induced changes (Isaac et al., 2017).

Malondialdehyde has been reported to be one of the end-products of lipid peroxidation, and its magnitude is measured by concentration of MDA in tissues (Eze et al., 2008). The alterations on the surface of erythrocyte membranes caused by lead intoxication could be responsible for the increased MDA concentration obtained in the lead exposed untreated group, and thus, suggests increased formation of free radicals by the heavy metal. Exposure to lead may alter antioxidant defense mechanism, which results in an imbalance 


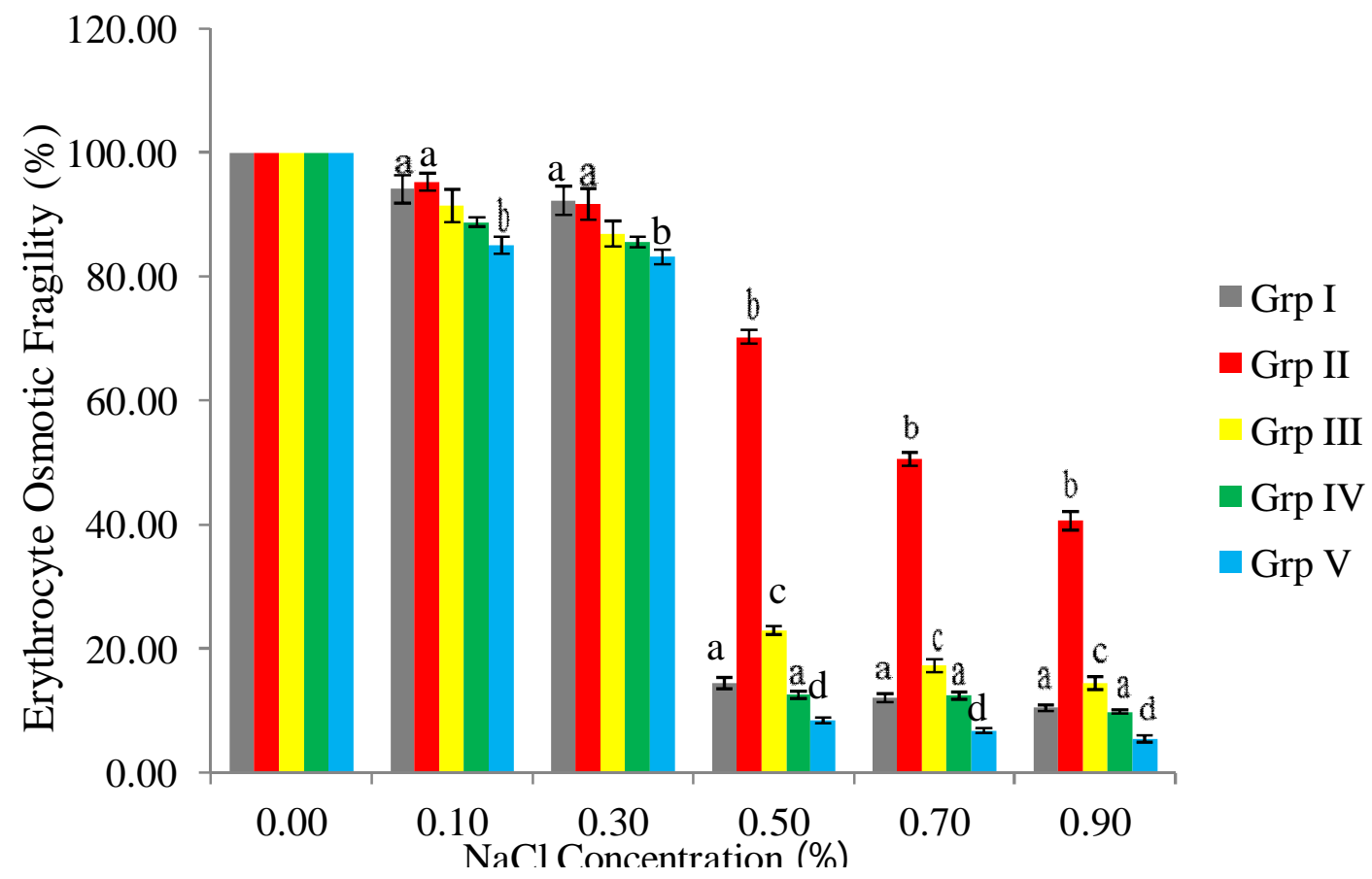

Figure 1. Effect of treatments with DMSA and/or Daflon ${ }^{\circledR}$ on the erythrocyte osmotic fragility of rats experimentally exposed to lead (means \pm SEM, $n=8$ ). a, b, c, d values with different superscripts are statistically significant $(P<0.05)$. Keys: Grp I, unexposed untreated (DW); Grp II, exposed untreated $(\mathrm{Pb})$; Grp III, exposed with lead and treated with $10 \mathrm{mg} / \mathrm{kg}$ bw DMSA (Pb + DMSA); Grp IV, exposed with lead and treated with $100 \mathrm{mg} / \mathrm{kg}$ bw Daflon ${ }^{\circledR}(\mathrm{Pb}+\mathrm{DAF})$; Grp V, exposed with lead and treated with $10 \mathrm{mg} / \mathrm{kg}$ bw DMSA and $100 \mathrm{mg} / \mathrm{kg}$ bw Daflon ${ }^{\circledR}(\mathrm{Pb}+\mathrm{DMSA}+\mathrm{DAF})$.

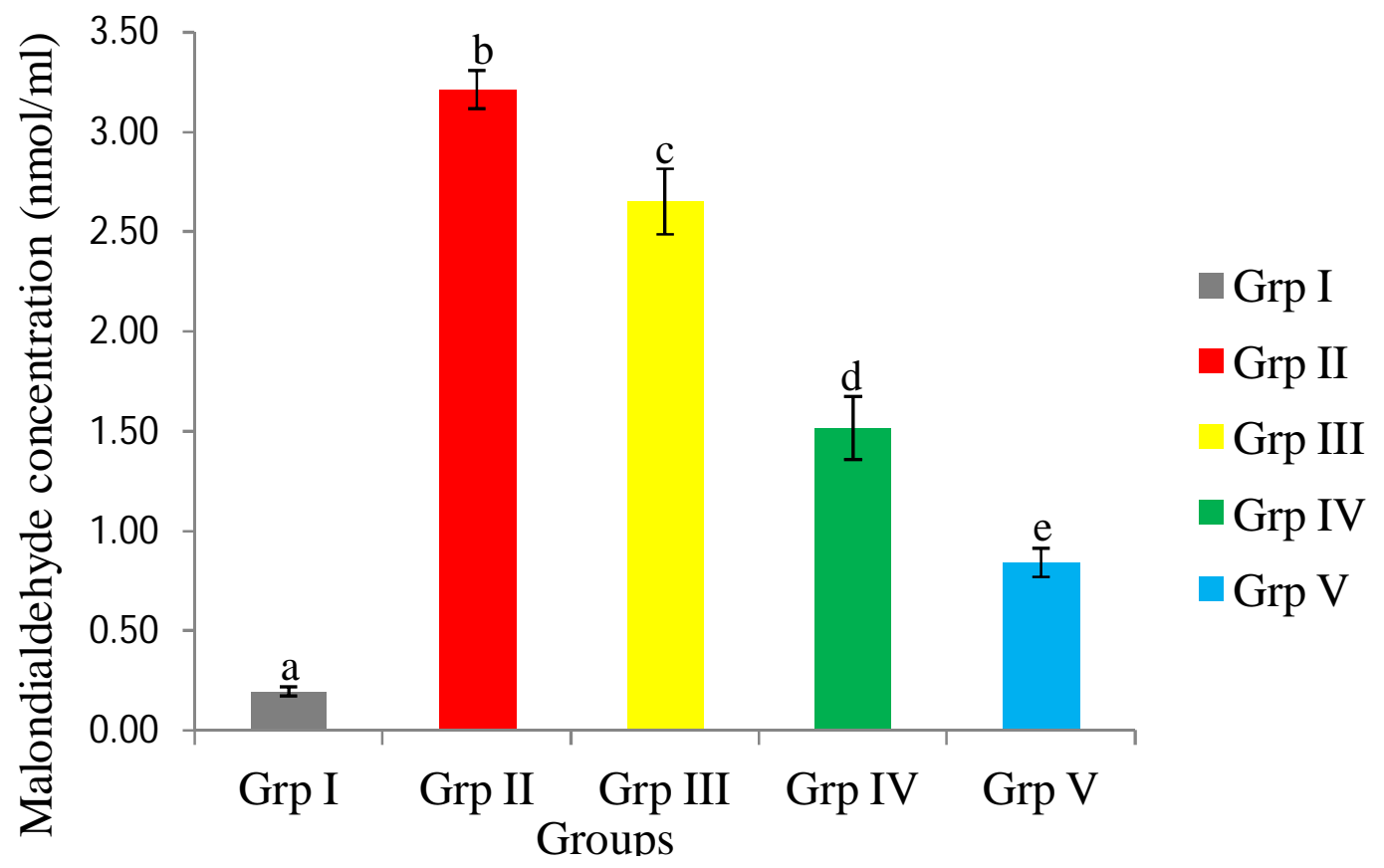

Figure 2. Effect of treatments with DMSA and/or Daflon ${ }^{\circledR}$ on malondialdehyde concentration of rats experimentally exposed to lead (mean \pm SEM, $n=8$ ). a, b, c, d, e values with different superscripts are statistically significant $(P<0.05)$. Keys: Grp I, unexposed untreated (DW); Grp II, exposed untreated $(\mathrm{Pb})$; Grp III, exposed with lead and treated with $10 \mathrm{mg} / \mathrm{kg}$ bw DMSA (Pb + DMSA); Grp IV, exposed with lead and treated with $100 \mathrm{mg} / \mathrm{kg}$ bw Daflon ${ }^{\circledR}$ (Pb + DAF); Grp V, exposed with lead and treated with $10 \mathrm{mg} / \mathrm{kg}$ bw DMSA and $100 \mathrm{mg} / \mathrm{kg}$ bw Daflon ${ }^{\circledR}$ (Pb + DMSA + DAF). 
between radical-generating and radical-scavenging activities, and consequently, the formation of oxidation products. The finding of elevation in MDA concentration in lead exposed animals is consistent with the result obtained in previous studies (Aksu et al., 2012; Nisar et al., 2013; Wang et al., 2013; Okediran et al., 2017), verifying that exposure to lead causes an increase in MDA concentration. The significant increase in MDA concentration produced by exposure to lead suggests an increase in lipid peroxidation, which is an indicator to increased levels of free radicals in the serum and tissues of lead exposed rats. Antioxidants have been reported to play an important role in mitigating lead-induced perturbations by sequestering heavy metal ions, thereby preventing metal-mediated generation of free radicals, and accordingly protecting the potential biological targets from oxidative damage (Lamidi and Akefe, 2017). The lead exposed and Daflon ${ }^{\circledR}$ treated groups showed significantly lower MDA concentration; thus, suggesting the ability of Daflon ${ }^{\circledR} 500 \mathrm{mg}$ as an effective antioxidant to ameliorate the oxidative stress, which is usually associated with lead toxicosis.

The decrease in EOF and serum MDA concentration, observed in groups treated with Daflon ${ }^{\circledR} 500 \mathrm{mg}$ and/or DMSA showed that Daflon ${ }^{\circledR} 500 \mathrm{mg}$, a bioflavonoid mixture, ameliorated the oxidative damages caused by lead exposure. DMSA on the other hand, a metalchelator drug, was able to chelate lead to some extent and, thus, protected the erythrocytes from the effect of lead-induced oxidative damage. This finding may be responsible for the more significant decrease in the percentage hemolysis and serum MDA concentration obtained in the group exposed to lead and treated with the combination of DMSA and Daflon ${ }^{\circledR}$. The result of the present study demonstrated the beneficial role of flavonoid administration in lead toxicosis.

\section{Conclusions}

Experimental exposure of rats to lead caused an increase in EOF and lipid peroxidation, and the administration of Daflon $^{\circledR}$ ameliorated the damages. It is therefore conceivable that the flavonoid mixture was suitable to alleviate the deleterious effect in lead toxicity through its cytoprotective, osmoregulatory, and membrane stabilization properties.

\section{ACKNOWLEDGEMENT}

The authors are grateful to the technical staff of the Department of Veterinary Pharmacology and Toxicology, Ahmadu Bello University Zaria, for their technical support.

\section{REFERENCES}

Adnan JMA, Sanaa KS, Nadhum AA, 2017. Biochemical study of the effects of some heavy metals on oxidant/antioxidant status in gasoline station workers /Basra-Iraq. Int J Sci Res Pub, 7(2): 83-94.

Aksu DS, Didin M, Kayikci F, 2012. The protective role of polyphenols on blood cells in rats exposed to lead. Rev Română Med Lab, 20(3): 233-243.

Ambali SF, Abubakar M, Shittu M, Yaqub LS, Anafi SB, Abdullahi A, 2010. Chlorpyrifos-induced alteration of haematological parameters in Wistar rats: ameriolative effect of zinc. Res $\mathrm{J}$ Environ Toxicol, 4: 55-66.

Asala OO, Ayo JO, Rekwot PI, Minka NS, Omoniwa DO, Adenkola AY, 2011. Effect of ascorbic acid administration on erythrocyte osmotic fragility of pigs transported by road during the hot-dry season. Vet Res Comm, 35: 245-254.

Canadian Council on Animal Care Guide (CACC), 1993. http://www.ccac.ca/en-/standards/ guidelines/, vol. 1 (second ed.). (Accessed June 17, 2011).

Cheong MJ, Roh YB, 2006. Protective effects of activated charcoal on the acute damages of kidney of mouse by lead. Korean $\mathrm{J}$ Elect Mic, 36: $57-72$.

Debosree G, Sudeshna P, Shamreen N, Debajit B, Mousumi D, Arnab KG, Syed BF, Aindrila C, Russel JR, Debasish B, 2016. Melatonin protects against lead acetate induced oxidative stress-mediated changes in morphology and metabolic status in rat red blood cells: A flow cytometric and biochemical analysis. J Pharm Res, 10(6): 381402.

Eze Jl, Anene BM, Chukwu CC, 2008. Determination of serum and organ malondialdehyde (MDA) concentration, a lipid peroxidation index in Trypanosoma brucei-infected rats. Comp Clin Path, 17(2): $67-72$.

Faulkner WR, King JW, 1970. Manual of Clinical Laboratory Procedures. Chemical Rubber Company, Cleveland, Ohio, USA, pp. 345.

Flora SJS, 2002. Nutritional components modify metal absorption, toxic response and chelation therapy. J Nutr Environ Med, 12: 53-67.

Isaac AO, Joseph AO, Victor SO, Lamidi YI, Andrew AM, 2017. Ameliorative effects of kaempferol and zinc gluconate on erythrocyte osmotic fragility and haematological parameters in Wistar rats exposed to noise stress. Insights Biomed, 2(3): 1-7.

Jalali MS, Seyedeh NH, Mousavi M, 2017. Comparative effect of silymarin and D-penicillamine on lead induced hemotoxicity and oxidative stress in rat. Iran J Toxicol, 11(3): 12-18.

Kessel I, O'Connor JT, 2001. Getting the Lead Out, the Complete Resource for Preventing and Coping with Lead Poisoning. Cambridge, MA: Da Capo press.

Kolanjiappan K, Manoharan S, Kayalvizhi M, 2002. Measurement of erythrocyte lipids, lipid peroxidation, antioxidants and osmotic fragility in cervical cancer patients. Clin Chim Acta, 326: 143-149.

Lamidi IY, Akefe IO, 2017. Mitigative effects of antioxidant in lead toxicity. Res Rep Toxicol, 1(3): 1-9.

Maikai VA, Kobo PI, Maikai BVO, 2011. Antioxidant properties of Ximenia americana. Afr J Biotechnol, 9(45): 7744-7746.

Nisar NA, Sultana M, Waiz HA, Para PA, Baba NA, Zargar FA, Raja $\mathrm{WH}$, 2013. Experimental study on the effect of vitamin $\mathrm{C}$ administration on lipid peroxidation and antioxidant enzyme activity in rats exposed to chlorpyriphos and lead acetate. Vet World, 6(8): 461466.

Okediran BS, Biobaku KT, Olaifa FH, Atata AJ, 2017. Haematological and antioxidant enzyme response to lead toxicity in male Wistar rats. Ceylon J Sci, 46(2): 31-37.

Oyewale JO, 1991. Osmotic fragility of erythrocytes of guinea fowls at 21 and 156 weeks of age. Vet Archiv, 61(1): 49-56.

Patrick L, 2006. Lead toxicity, a review of the literature. Part 1: Exposure, evaluation, and treatment. Altern Med Rev, 11: 2-22.

Rizk SM, Sabri NA, 2009. Evaluation of clinical activity and safety of Daflon $500 \mathrm{mg}$ in type 2 diabetic female patients. Saudi Pharm J, 17: 199-207.

Saluja PS, Gupta SL, Malhotra DV, Ambawat HK, 1999. Status of plasma malondialdehyde in experimental $T$. annulata infection in crossbred bovine calves. Indian Vet J, 76: 379-381.

Terao J, 2009. Dietary flavonoids as antioxidants. Forum Nutr, 61: 8794

Wahab AA, Mabrouk MA, Ayo JO, Ambali SF, Shittu M, Adenkola AY, 
Salawu EO, 2010. Effects of co-administration of antioxidants on erythrocyte osmotic fragility of Wistar rats during the hot-dry season. Eur J Sci Res, 46(1): 73-79.

Wang J, Zhu H, Yang Z, Liu Z, 2013. Antioxidative effects of hesperetin against lead acetate-induced oxidative stress in rats. Indian J Toxicol, 45(4): 395-398.

Warang $\mathrm{P}$, Colah R, Kedar $\mathrm{P}, 2017$. Lead poisoning induced severe hemolytic anemia, basophilic stippling, mimicking erythrocyte pyrimidine 5 '-nucleotidase deficiency in beta thalassemia minor. $J$ Clin Toxicol, 7(2): 346.

Weisman A, Chou B, O'Brien J, Shea KJ, 2015. Polymer antidotes for toxin sequestration. Adv Drug Delivery Rev, 90: 81-100.
Citation: Yusuf IL, Akef IO, Tijjani MB, Yusuf H, Salihu SI, M uhammad Z, 2018. Lead-induced increase in erythrocyte osmotic fragility and malondialdehyde concentration in W istar rats: Chemoprotective effects of flavonoid mixture. Biochem Biotechnol Res, 6(1): 9-14. 